\title{
Para começar um projeto de pesquisa
}

José Luiz Braga

Doutor em Comunicação pela Universidade de Paris 2 (Institut Français de Presse).

Professor titular no Programa de Pós-Graduação em Comunicação (mestrado e doutorado)

da Unisinos. Desenvolve pesquisa sobre os sistemas críticos da mídia e sobre a interface

Comunicação-Educação.

E-mail: jbraga@unisinos.br

Fazer pesquisa solicita uma diversidade de reflexões e gestos mais ou menos complexos. É por isso que não vamos diretamente a campo para investigar - fazemos antes um cuidadoso planejamento, o qual se expressa em um projeto de pesquisa. Como o projeto vai se desenvolvendo ao longo do próprio trabalho de investigação (não paramos nunca de planejar), podemos chamar as fases iniciais de pré-projeto - ou, mais inicialmente ainda, de uma proposta de pesquisa. Assinalo que estou enfocando particularmente esse planejamento inicial: a proposta.

Quero enfatizar a particular centralidade, nesse planejamento, do problema de pesquisa. Só pesquisamos porque temos dúvidas a respeito de alguma questão do mundo. É lógico portanto que as dúvidas que temos (e que serão expressas no problema da pesquisa a realizar) devem comandar todo o trabalho de investigação - desde a busca das teorias e conceitos relevantes até a observação da realidade (coleta de dados), o tratamento desses dados e as conclusões ou inferências -, que correspondem ao conhecimento desenvolvido a partir do problema que nos moveu a investigar.

Geralmente os manuais de metodologia de pesquisa enfatizam como ponto de partida para investigação uma hipótese de pesquisa. Esta se baseia na afirmação (hipotética, justamente) que seria investigada a fim de confirmarmos, ou não, se efetivamente corresponde aos fatos. Consideramos que, nas pesquisas qualitativas, essa insistência pode levar a equívocos.

A pretendida necessidade da hipótese de pesquisa leva a um esforço do pesquisador para apresentar alguma coisa que seja aceita como tal. Como nós sempre temos idéias, impressões e propostas referentes aos temas que nos interessam (e que nos motivam a pesquisar), é fácil decidir que uma dessas proposições é nossa hipótese. Tipicamente, entretanto, se trata de premissas ou de sacações (no dicionário Houaiss: "idéia, invenção, lampejo". Refere-se ao habitual anglicismo insight). Os lampejos correspondem àquelas idéias explicativas ou interpretativas que acabamos descobrindo de modo espontâneo por nos envolvermos continuadamente com um tema, por experiência prática ou por leituras. 
O processo do insight, ou lampejo, seria o seguinte. Trabalhamos com um assunto qualquer (por exemplo, questões referentes à estética publicitária ou à violência na TV, entre outras). Observamos o que as pessoas fazem e dizem, lemos a respeito. De repente percebemos perspectivas que ninguém parece ter ainda notado - é o nosso insight. Como estamos pretendendo fazer uma pesquisa, a forte tendência é tomar essa idéia como nossa hipótese - nos propomos a pesquisar para ver se é ou não verdadeira.

Dificilmente seria uma boa hipótese. Trata-se talvez de um bom ponto de partida. Mas se o final da investigação nos levar de volta a ele, apenas fizemos um círculo para chegar ao lugar de onde saímos, confirmando o que já sabíamos.

Seria possível dizer (alguns pesquisadores nessa situação efetivamente o dizem): "Mas talvez a gente acabe provando que a hipótese não é verdadeira e, portanto, há realmente alguma coisa a investigar”. Além de ser frustrante fazer uma pesquisa apenas para provar que estamos errados, isso dificilmente ocorrerá. Primeiro, porque, motivados pelo insight, trabalharemos tendencialmente para provar essa idéia - gerando uma cegueira involuntária para todos os dados que a contrariem. Segundo, porquanto provavelmente uma idéia gerada por forte envolvimento com a situação é mesmo verdadeira (isto é, válida para o espaço e conjuntura em que foi proposta) e se sustenta pela própria constatação ao vivo, sem precisar de pesquisa para o demonstrar.

Não estou sugerindo que se jogue fora aquela idéia brilhante (seria frustrante, não é?), mas apenas que ela não seja usada como hipótese de pesquisa. Mais adiante faremos sugestões de bom uso para os insights (se eles existirem). Contudo, desde já assinalamos que não é preciso ter idéias brilhantes iniciais, fulgurações conceituais ou propostas salvadoras.

Às vezes você tem em mãos (se tiver, mas não é necessário) uma hipótese de trabalho. Esta, diferente da hipótese de pesquisa, é usada como base para organizar a observação. A questão (ou problema da pesquisa) pode tomar então a seguinte forma: se esta hipótese é verdadeira (e trabalharemos como se fosse), o que poderemos descobrir sobre os processos em pauta, estando munidos de tal afirmação? Note que aqui não vamos investigar a hipótese, mas sim tomá-la de antemão como verdadeira e usá-la como modo ou instrumento para direcionar as observações.

Para evitar, em uma proposta de pesquisa, confundir premissas, lampejos e hipóteses de trabalho com hipóteses de pesquisa, talvez a melhor tática, para o iniciante, seja a de não apresentar nenhuma hipótese pretendida como "de pesquisa”. Em vez disso, apresente diretamente seu problema de pesquisa.

\section{A DÚVIDA E A CURIOSIDADE COMO BASE}

Dissemos que ter lampejos, idéias brilhantes iniciais e hipóteses de pesquisa não é necessário. Outra coisa, entretanto, é fundamental: curiosidade. É preciso estar curioso a respeito de uma situação ou tema. Ou seja: deve-se ter dúvidas, reconhecer que não sabemos alguma coisa sobre a questão de nosso interesse. 
É por isso que um problema de pesquisa toma, freqüentemente, a forma de uma pergunta. "O que será que...?"; "Como tal coisa se caracteriza?"; "Que sentido tem...?”; "Por que tal processo acontece?”; "Que diferenças existem entre...?”; "Quais as formas diversificadas e variações de tal processo comunicacional?".

No espaço da comunicação ou da educação, não é difícil encontrar problemas, situações problemáticas, dificuldades, estímulos à curiosidade. O espaço da comunicação, para você, pode estar relacionado a uma formação em determinada área (jornalismo, publicidade, relações públicas, audiovisuais); a um campo de interface (outras formações sociais/culturais com percepção de questões comunicacionais); a uma experiência profissional correlata; a leituras sobre questões pertinentes; ou até mesmo à simples situação de usuário interessado da mídia (espectador de programas de TV, leitor de jornal, usuário da internet, aficionado de filmes cinematográficos etc.). Na educação, os problemas práticos de obter aprendizagem, de aprender, de organizar e gerir atividades de ensino podem estar ligados a todas as atividades humanas e sociais.

Ora, não é qualquer não saber que pode gerar diretamente pesquisa. Vamos afastar alguns não saberes a fim de evitar riscos. Primeiro, aqueles que, para serem supridos, basta uma ida à biblioteca. Eu não sei uma porção de coisas, entretanto, posso prever que alguém saiba (tipicamente: o especialista, o professor, os livros). Nossas dúvidas, aí, não levam à pesquisa, mas ao estudo. Claro que, em uma pesquisa, aparecem também questionamentos, que serão resolvidos na biblioteca ou em consulta a especialistas. Mas não formam o eixo da pesquisa. São complementares.

Além disso, faça outra triagem: distinga problemas de conhecimento de problemas práticos. São os primeiros que direcionam à pesquisa. Um problema prático pede solução, a qual é geralmente desenvolvida por meio de interferências no ambiente mesmo das situações problemáticas, tipicamente profissionais ("O que fazer para que...?”; "Como obter mais qualidade em tal processo?”; "Como evitar equívocos de tal tipo?"; "Como resolver com mais eficiência este processo?”).

Quando tais problemas de situação são mais complexos, talvez seja necessário mais do que agir diretamente - e aí queremos trazer aportes científico-tecnológicos. Podemos então escrever elaboradas propostas, bem baseadas em conhecimento acadêmico, para o encaminhamento de soluções. Ainda assim, não se trata de pesquisa. Certamente podemos pensar em pesquisas de desenvolvimento, feitas em zona intermediária entre a pesquisa de conhecimento e ações propositivas práticas. Essa possibilidade não será entretanto aqui estudada.

Ficaremos, então, com os problemas de conhecimento: "o que é preciso saber sobre tal situação?"; "O que deveremos descobrir sobre ela para que nosso conhecimento da realidade em foco seja ampliado?”.

Como se pode perceber, podemos derivar um problema de pesquisa de um problema prático. Dada uma situação-problema na realidade, se essa situação é suficientemente complexa, em vez de procurar e propor soluções concretas imediatas, tentaremos direcionar a reflexão para: "como aprofundar meu conhecimento sobre essa situação antes de buscar soluções?”. 
O trabalho de aprofundar conhecimentos seria a pesquisa acadêmica. No caso de um mestrado, resultará em uma dissertação. As soluções concretas podem ser decorrentes da dissertação, mas já não fazem parte dela. Serão, se for o caso, expectativa para depois; e resultado de aplicações posteriores dos conhecimentos obtidos sobre a realidade social.

Por outro lado, não precisamos partir diretamente de situações problemáticas da realidade. Podemos começar com preocupações e curiosidades mais abstratas ou conceituais, com dúvidas sobre o sentido das coisas. Neste caso, porém, não se esqueça - em algum momento na elaboração de seu projeto - de relacionar essas questões com uma realidade específica. Pois não se investigam abstrações. Salvo nas pesquisas especulativas (mais próprias do trabalho em Filosofia ou nos espaços mais rarefeitos das fronteiras epistemológicas das Ciências Humanas e Sociais, que exigem longa formação e experiência prévia em pesquisa), trabalharemos tipicamente com investigações sobre questões relacionáveis diretamente à realidade social/expressional da comunicação ou da educação.

Muito bem... até aqui tivemos exclusões (do tipo não faça isto). O que não permite avançar-se muito, porque a questão não é o que não fazer, mas sim $o$ que fazer sobre o que não sabemos, sobre nossa curiosidade, que se deve expressar em um não saber especificado, para gerar pesquisa.

\section{PARA COMEÇAR A CONSTRUIR O PROBLEMA DA PESOUISA}

Sabemos, então (aproximadamente), o tipo de problema que nos interessa para fazer pesquisa, em torno de um tema de nosso interesse. Mas ainda não temos certeza de como elaborar e expressar um problema de pesquisa.

É claro que naturalmente não há receitas para isso. Constrói-se um problema de pesquisa de muitas e muitas formas diferentes. Além disso, construir um problema de pesquisa não corresponde simplesmente a descobrir a questão e a escrever. É um processo de elaboração que se pode desenvolver em várias fases diferentes da própria pesquisa - evoluindo à medida que estudamos autores, fazemos pré-observações e pensamos metodologicamente sobre como abordar nosso objeto.

Mas nossa questão aqui - felizmente - é bem mais simples. Trata-se apenas de prefigurar um problema de pesquisa; em dar a partida, em ter um questionamento inicial em que se agarrar para poder depois, já na pesquisa, dar outros passos.

Façamos então o seguinte.

Como primeiro passo, escreva tudo o que você já sabe sobre o tema de seu interesse. Inclua aí dados de experiência prática, observações casuais que tenha feito sobre o objeto que lhe chama a atenção, leituras recentes, leituras ad hoc (ou seja, já realizadas em decorrência de estar pretendendo elaborar uma proposta sobre o tema). Não se esqueça de incluir, é claro, aquelas idéias fulgurantes, as sacações referidas antes (se existirem, mas lembrando que não são necessárias). 
Lembre-se também de identificar as diferentes origens do que você já sabe (leituras, experiência etc.). No caso de leituras, não se esqueça de citar os autores, livros, número das páginas.

Note: esse texto não é ainda o seu projeto. É apenas um documento preparatório, uma peça para ficar nos bastidores e que não irá à cena. Sinta-se livre, portanto, para escrever o que quiser, da forma que preferir. Nenhum professor vai ler isso - você estará escrevendo para si mesmo.

Só o fato de ter alinhado essas proposições, se você tem sorte, já lhe terá deixado cheio de dúvidas. Supere aquelas existenciais, as referentes a sua competência para tratar do assunto e para fazer pesquisa, e selecione apenas as que dizem respeito ao próprio objeto.

Passemos então ao segundo passo da elaboração - sempre nos bastidores, sempre escrevendo apenas para você. Utilize as dúvidas percebidas, mobilize sua curiosidade e comece a escrever perguntas; tudo que você consiga perguntar. Nesse momento, não se preocupe se são relevantes ou não, se são brilhantes ou simples. É uma fase de brainstorm (se não sabe o que é, que tal ir ao dicionário?). O prêmio aqui não é para as boas questões, mas para a maior diversidade.

Você poderá então passar ao terceiro passo, que é, naturalmente, a crítica das perguntas. Distinga as que expressam apenas falta de informação e de maiores estudos. Você desconfia que esse conhecimento já existe em algum lugar e que precisará dele para fazer avançar a pesquisa, mais tarde. Guarde cuidadosamente tais perguntas para que o ajudem a procurar informações, mas perceba que elas não comporão diretamente seu problema de pesquisa.

Separe ainda as questões práticas, isto é, aquelas que pedem soluções concretas, ações, propostas diretas sobre o que fazer. Esse conjunto não tem uso central para a construção do problema de pesquisa. Mas reserve-as para uma segunda rodada de brainstorming. Verifique aí se não é possível derivar delas dúvidas de conhecimento. Além disso, se são perguntas práticas complexas e relevantes, podem servir como meta posterior à pesquisa, ou seja, a pesquisa buscará conhecimentos que sejam depois úteis para encaminhar soluções para os problemas de realidade (e isso deve, mais tarde, ser indicado em sua proposta).

Discrimine também as perguntas para as quais você já tem resposta. É fundamental ser muito sincero com você mesmo. A resposta pode ser aquela sacação que você gostaria muito que fosse a conclusão da pesquisa - mas aí não vale, porque esta já estaria concluída antes de ser começada. Pode ser, ainda, que a resposta seja uma proposição argumentativa elegantemente direcionada pela pergunta. Nesse caso, trata-se do que chamamos de pergunta retórica, ou seja, ela não pede uma resposta, como uma questão comum, apenas encaminha um argumento. Exemplo: "Seriam os usuários de TV passivos diante da programação que recebem?" - encaminhando a resposta: "Não, pois percebemos que cada espectador reage diferentemente aos programas, gerando variadas interpretações. Logo, estão ativamente fazendo interagir seus repertórios pessoais (variados) com o que diz e mostra a programação". 
Para o caso das perguntas que já têm ou presumem respostas, veja se as proposições feitas na primeira fase de nosso exercício (alinhar tudo o que você já sabe sobre o tema) mais ou menos coincidem com as respostas implícitas. Em caso negativo, pense em transferir esse material para aquele documento preparatório, já agora na forma de propostas afirmativas e não mais interrogativas.

Separe ainda as questões amplas demais, muito genéricas e vagas, que você não consiga relacionar a uma busca especificada de conhecimento. Lembre-se de que você vai investigar (ou seja: vai olhar sistematicamente um pedaço da realidade) para procurar encaminhamentos para seu problema. Assim, perguntas muito amplas ou vagas não são pertinentes - ou você não saberia o que olhar na realidade; ou teria que observar uma realidade muito ampla, diversificada e complexa (e não daria tempo).

Por exemplo: "Como a comunicação midiática modifica os processos de aprendizagem tradicionalmente ancorados no livro?”. Interessantíssima questão. Entretanto, não é diretamente pesquisável. Se eu tiver suficiente experiência na área (interface comunicação/educação) e as leituras adequadas, poderei escrever um belo ensaio em, digamos, dois meses de trabalho. Mas não conseguirei investigar a questão diretamente nesse nível de abrangência, nem mesmo em dez anos de pesquisa.

Distinga o conjunto acima, mas não jogue fora essas perguntas. Elas talvez tenham forte utilidade para definir o horizonte em função do qual o problema pode ser construído. É por isso que insisti antes na palavra diretamente. Pois quem sabe indiretamente signifique questões relevantes. Você poderá então tentar derivar perguntas mais específicas a partir delas - nesse caso, mantenha as questões gerais como seu horizonte e construa o problema em torno das específicas.

É possível que você tenha, no seu elenco, algumas perguntas do tipo sim/ não. São aquelas que oferecem apenas uma possibilidade binária exclusiva de resposta: ou uma coisa, ou outra. É raro (embora não impossível) que essas questões sejam bom eixo de pesquisa. Primeiro porque, quando são tão dramaticamente contrapostas, já temos uma preferência por uma das alternativas (o que nos remete às perguntas com respostas prontas). Depois, porque a realidade sociocultural e o sentido das coisas dificilmente são tão simplificados para permitir dualidades mutuamente excludentes. Alternativamente: ou a contraposição é justamente simples, e não exige pesquisa, ou é caso antes de tomada de posição do que de busca de conhecimento, e não exige pesquisa.

O mais freqüente é que uma pergunta desse tipo na verdade esteja reduzindo uma realidade mais complexa, que não deveria portanto estar sendo apreendida em termos de ou isso ou aquilo. E aí, qualquer que seja a alternativa resultante da investigação - sim ou não -, torna-se pobre ou claramente falseadora da situação.

Assim, se você tem alguma pergunta elaborada dessa forma, em vez de descartá-la, procure derivar dela questões mais sutis ou complexas - do tipo Como? -, que se mantêm abertas, pois podemos encontrar diversos como em 
vários níveis (ou seja, diferentes modos e formas de um processo ou fato). Ou, ainda, tente perguntas como: "Que diferenças podem ser percebidas [em alguma coisa que parece em geral monolítica]?”. E também: "Que semelhanças podemos encontrar [em coisas que parecem diferentes ou isoladas entre si]?”. É claro que interrogações dessa natureza dependem de que já estejamos desconfiados das diversidades (ou das similaridades, na segunda alternativa). Mas note que a questão não é "Há diferenças internas na situação dada como monolítica?" (resposta sim ou não). Procurar diferenças e variações decorre da prévia perspectiva do sim - e a busca será de quais?, questão aberta à descoberta.

Feitas as distinções anteriores, você deve ter agora um conjunto (mesmo pequeno) de perguntas mais ou menos específicas, mais ou menos indicadoras para o trabalho de investigação (observação, trabalho de campo, exame de textos e materiais audiovisuais - obtenção de dados).

Se forem muito poucas e você sentir que estão ainda fraquinhas, tente uma segunda rodada de geração de perguntas - novas ou derivadas das perguntas amplas, das perguntas práticas e das do tipo sim/não. Ao final de um certo exercício nessa direção, tendo chegado a um conjunto de questões mais ou menos aceitas (por você mesmo, é claro), passaremos ao exercício seguinte que será nossa quarta fase, a de sistematização das perguntas.

Note que não é preciso ter um grande número de interrogações para construir um problema de pesquisa. É melhor mesmo que sejam poucas, pois o importante é a consistência do conjunto e, particularmente, sua relevância e possibilidade de efetivamente demarcar a curiosidade que você tem sobre o assunto.

Como quarto passo, procure então organizar as perguntas - mais relevantes e secundárias; mais amplas e mais específicas; independentes entre si ou relacionadas; relacionadas em paralelo ou por subordinação; mais teóricas ou mais voltadas para a busca de dados etc.

Os modos de organizar vão depender, é claro, do conjunto específico de questões que você gerou. $\mathrm{O}$ objetivo principal, aqui, é ultrapassar o nível de perguntas soltas e chegar a um padrão de consistência em que se perceba um conjunto integrado, internamente relacionado, de perguntas.

Faça isso como um jogo de armar - tente uma alternativa, um "desenho", e depois outro e outro, até ficar satisfeito. Não fique, porém, satisfeito cedo demais: brinque um pouco com as possibilidades.

No decorrer do processo, é possível que você tenha a tendência de reformular algumas questões, de criar outras, de substituir alguma coisa. Sinta-se à vontade: as perguntas são suas.

No quinto passo, quando tiver chegado a um conjunto mais ou menos consistente, veja se consegue escrever um pequeno texto para "explicar" o que é tal conjunto, por que ele é interessante, como efetivamente configura sua curiosidade sobre o tema.

Não é preciso insistir que esses exercícios são iterativos, isto é, podem (e devem) ser reiterados, em um processo de ida e volta entre: as proposições iniciais sobre o tema; as perguntas (em sua variedade de tipos); a crítica das 
perguntas; o conjunto de construção de consistência no questionamento; e o texto sobre o interesse das perguntas.

Os documentos elaborados nas diferentes fases do exercício não são ainda a proposta de pesquisa, porém constituem aqueles documentos preparatórios, de bastidores. Mas ao chegar a um conjunto consistente de perguntas (para sua satisfação) e conseguir o texto explanatório sobre seu questionamento, você terá então os materiais necessários para começar a escrever a proposta. Faça, assim, um texto claro, pensando em um leitor que possa compreender seu projeto. Use o que for possível e interessante, dos documentos preparatórios, no texto da proposta. Lembre-se de que você não está escrevendo um artigo; dessa forma, evite respostas antecipadas e um tom de terminalidade. Mantenha o texto aberto para futuros desenvolvimentos e não esconda suas dúvidas.

Não se preocupe excessivamente com o atendimento desses passos, como se fossem uma receita rígida. Tome suas próprias decisões. Tais indicações são genéricas, e sua construção de problema é específica. Você pode, então, se sentir mais produtivo deixando de lado alguma coisa e inventando outras táticas.

\section{RELAÇÕES ENTRE PROBLEMA E OBSERVAÇÃO}

Em uma fase inicial, os desenvolvimentos teóricos e o planejamento da observação podem ser ainda bastante preliminares. No momento - e com relação à construção do problema de pesquisa -, quero apenas chamar a atenção para duas ou três idéias básicas sobre relações entre o problema de pesquisa e o trabalho concreto de investigação.

Deve haver uma forte coerência entre o problema de pesquisa e a percepção da realidade (investigação propriamente dita). Mesmo que a previsão detalhada das verificações a serem feitas corresponda a uma etapa posterior de planejamento, é importante pensar desde já no que você pretende observar sistematicamente.

Primeiro, para prefigurar o que será seu trabalho de campo. Você vai entrevistar pessoas? Quantas? Onde? Examinará produtos midiáticos (programas de TV, sites de internet, fotografias)? Acompanhará experiências pedagógicas? Quais, quantas, segundo que perspectivas? Irá observar diretamente pessoas em atividade no mundo real (interagindo na internet, o público de um festival de cinema, uma redação de jornal, uma escola)? Que situações específicas interessam? Como vai observar (participando do grupo, apenas olhando, fazendo perguntas)? Para obter que tipos de dados?

Como se vê, uma listagem seria infinda. Pensar em suas alternativas específicas é relevante, porque essa vai ser a investigação propriamente dita. Você ocupará uma boa parte do seu tempo fazendo tais coisas - e não deve ser apanhado de surpresa, na hora da investigação, sem saber direito o que fazer, nem descobrir de última hora que aquele problema exige certas observações.

Mas há uma outra razão para pensar nisso desde o começo. Você deve decidir se as observações que está pensando em fazer são coerentes com o 
problema de pesquisa que começou a construir. Aquele problema, apresentado daquele modo, será adequadamente gerador de conhecimentos através dessas observações?

Assim, prefigurar as observações é um bom teste para a qualidade da construção do problema. Caso as observações imaginadas não pareçam estar bem articuladas com o problema, tente decidir se outras seriam melhores, mais ajustadas. Mas também é possível que as observações pretendidas sejam interessantes. Neste caso, faça uma boa revisão em suas perguntas para ajustálas ao trabalho investigativo que está querendo fazer. Elas serão aperfeiçoadas, ajudando a desenvolver o problema de pesquisa.

Você terá, assim, iniciado - concretamente - seu projeto de pesquisa. A partir daí, as buscas teóricas virão - a serviço do projeto e não como abstração desconectada. Pode ser um bom começo.

Resumo: O presente artigo, dirigido a estreantes em pesquisa, trata dos movimentos reflexivos e construtivos iniciais para desenvolver um projeto. Depois de propor que a habitual insistência em hipóteses de pesquisa pode levar a equívocos, quando se trata de pesquisas qualitativas, enfatiza o trabalho preliminar de construção do problema de pesquisa. Explicita características mínimas de um problema adequado, afastando tipos de problema pouco promissores. Apresenta então, sobre esta base, indicações práticas para tal construção, através de um exercício em cinco passos ou fases. Finalmente relaciona a previsão da observação (investigação propriamente dita) com a construção do problema.

Palavras-chaves: projeto de pesquisa, problema de pesquisa, investigação.
Abstract: This article, addressed to beginners in research, comments on the constructive initial movements to develop a project. After proposing that the usual claim for research hypothesis may lead to flaws in qualitative research, it emphasizes the preliminary work of constructing the research problem. It lists basic characteristics of an adequate problem, discarding nonpromising types. Upon that basis, it proposes some topics on problem construction, by means of a five steps exercise. Finally, it suggests a relationship between the plan of observation (the investigation itself) and the construction of the problem.

Keywords: research project, research problem, investigation. 